\title{
Kronisk suicidalitet ved ustabil personlighetsforstyrrelse. Hvorfor det er behov for særskilte tilnærminger i behandlingen
}

Ved Joel Paris

\begin{abstract}
De tilnærmingene som er utviklet for å behandle akutt suicidalitet, er ikke nødvendigvis effektive for behandling av kronisk suicidalitet. Kroniske selvmordstanker er et viktig kjennetegn ved ustabil personlighetsforstyrrelse (UPF). Hos disse pasientene fyller suicidaliteten en rekke psykologiske funksjoner og kan bli en levemåte. Selvmordstanker og -forsøk er svært utbredt blant disse pasientene, mens selvskading ved kutting ofte benyttes som en måte å regulere affekter på. Til forskjell fra akutt suicidalitet er ikke selvmordstanker et episodisk fenomen, men vedvarer i årevis. Det er ganske uforutsigbart hvilke UPF-pasienter som vil ta sitt eget liv. Innleggelse i sykehus kan virke mot sin hensikt. Pasienter med kronisk suicidalitet bør derfor behandles poliklinisk.
\end{abstract}

\section{Fenomener knyttet til kronisk suicidalitet}

Termen "suicidalitet" brukes om tanker og atferd hos pasienter som tenker på selvmord, som kutter seg, tar mildere overdoser eller utfører livstruende handlinger. Pasienter som er kronisk suicidale, kan ha både selvmordstanker og de nevnte atferdstypene. Allikevel er hvert av disse scenariene forskjellige og trenger ulike behandlingstilnærminger.

Selvmordstanker forekommer hyppig i befolkningen, og er en dårlig prediktor for suicidale handlinger. I en finsk befolkningsstudie var forekomsten av selvmordstanker i en 12-måneders periode 4,6 \%, og livstidsprevalensen var 14,7 \% (Hintikka et al., 2001). Dette tilsvarer prevalensen for alvorlig depresjon (Weissman et al., 1996). Tilsvarende funn er fremkommet i USA i den nasjonale komorbiditetsstudien (Kessler et al., 2005). Så selv om forbigående selvmordstanker forekommer hyppig ved mild til moderat depresjon, vil de fleste pasientene aldri gjøre selvmordsfors $\varnothing \mathrm{k}$ (Maris et al., 2000).

I befolkningen som helhet er det en prevalens på 3 til $5 \%$ for selvmordsfors $\varnothing \mathrm{k}$ (Kessler et al., 2005; Welch, 2001).

Pasienter med kronisk suicidalitet gjør imidlertid ofte selvmordsfors $\varnothing \mathbf{k}$, og med lav dødelighet, vanligvis små overdoser (Gunderson \& Links, 2008). Dette mønsteret indikerer at de er ambivalente i sine intensjoner. Men skillet mellom dødelig og ikke-dødelig overdose kan tilsløres av pasientens mangel på kunnskap om hvilke legemidler som faktisk er farlige (Beck et al., 1974).

De fleste overdoser blant UPF-pasienter skjer i en mellommenneskelig kontekst (Gunderson \& Links, 2008), og de kan til og med finne sted med andre mennes- ker til stede. Selv ved de mest alvorlige selvmordsfors $\varnothing \mathrm{k}$ er som regel nærstående personer involvert, enten ved at det er de som finner pasientene, eller de følger dem til medisinske akuttmottak. Kronisk suicidale pasienter gj $\varnothing$ r ofte flere selvmordsfors $\varnothing \mathrm{k}$. Median livstidsfrekvens er tre fors $\varnothing \mathrm{k}$ (Soloff et al., 1997).

Hos kronisk suicidale pasienter har selvskading en helt annen psykologisk funksjon enn suicidaliteten, og selvskadingen har ingen suicidal intensjon. Det er et vanlig mønster at de gjør overfladiske kutt som ikke utgjør noen alvorlig fare (Leibenluft et al., 1987; Favazza, 1996). De fleste skjærer seg i håndleddene, men mange pasienter skjærer seg i armene og bena på lite synlige steder for å unngå kommentarer fra andre.

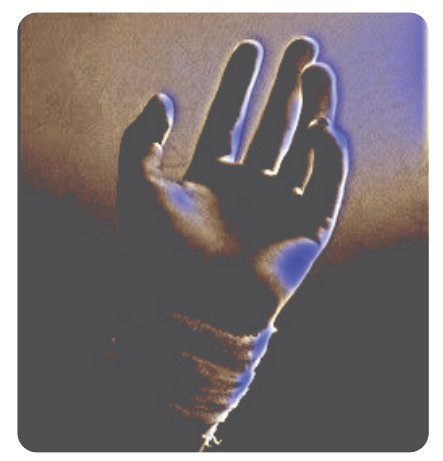

I en studie ble UPF-pasienter som gjør selvmordsfors $\varnothing \mathrm{k}$, sammenliknet med UPF-pasienter som skader seg selv i ikkesuicidal hensikt, og man fant at begge gruppene gav uttrykk for at hensikten med atferden vanligvis var å oppnå avlastning for negative følelser (Brown et al., 2002). Hensikten med selvmordsforsøket var å slippe unna, mens selvskadingen ble gjort for å uttrykke sinne, straffe seg selv, for å vekke normale følelser eller for å avlede oppmerksomheten fra de ubehagelige følelsene.

Fordi kutting gir en kortvarig regulering av intense, negative følelser, er det mange som kutter seg gjentatte ganger eller endog blir avhengige av det (Linehan, 1993). Ved å skade seg selv erstatter pasientene den psykiske smerten med fysisk smerte, eller de kan hensette seg i en dissosiert tilstand når de kutter seg og kjenner dermed lite smerte (Leibenluft et al., 1987; Simeon et al., 1992).

Det følger av definisjonen av kronisk suicidalitet at den ikke har den episodiske karakter som vi forbinder med akutt suicidalitet (Shneidman, 1973). Den er ikke relatert til depresjonsperioder, men til personlighetsforstyrrelse. Et mønster av suicidalitet som er kontinuerlig, repetitivt og fyller en mellommenneskelig funksjon, krever en annen tilnærming til behandling.

Vansker med å predikere selvmord ved kronisk suicidalitet

En rekke studier peker i retning av at 9 til $10 \%$ av pasienter med UPF til slutt vil ta sitt liv (Paris, 2003), men det er vanskelig å identifisere hvem som har høyest risiko for dette. Det meste av forskningen om risikofaktorer for selvmord i kliniske utvalg har fokusert på den akutte risikoen ved melankolsk depresjon, bipolar lidelse, alkoholisme og schizofreni. Men disse data fra slike studier gjelder ikke for kronisk suicidale pasienter. Mens antall selvmordsfors $\varnothing \mathrm{k}$ generelt er assosiert med en $\varnothing \mathrm{kt}$ livstidsrisiko for gjennomf $\varnothing$ rte selvmord (Maris et al., 2000), kommer ikke de fleste UPFpasienter som gjør mange selvmordsfors $\varnothing \mathrm{k}$ til å d $\varnothing$ av selvmord (Paris, 2003). 
Selv ved akutt suicidalitet er det vanskelig å predikere selvmord, først og fremst fordi selvmord forekommer så sjelden i forhold til selvmordsfors $\varnothing \mathrm{k}$. I to studier brukte man ulike algoritmer for å forutsi hvem som ville gjennomf $\varnothing$ re selvmord i utvalg av psykiatriske pasienter med mange statistisk signifikante risikofaktorer for selvmord (Goldstein et al., 1982).

Studien viste lav prediktiv kapasitet fordi det var et stort antall falske positive. Et annet problem er at de fleste som gjennomfører selvmord, gjør det på første for$s \varnothing \mathrm{k}$. I en amerikansk unders $\varnothing$ kelse gjennomførte $75 \%$ selvmord på første fors $\varnothing \mathrm{k}$, og blant dem over 45 år var $88 \%$ av gjennomf $\varnothing$ rte selvmord førstegangs forsøk (Maris, 1981). I en omfattende finsk befolkningsstudie fant man lignende resultater; $56 \%$ av selvmordene skjedde på første fors $\varnothing \mathrm{k}$ (Isometsä \& Lönnqvist, 1998).

Forskning har vist at de som gjennomfører selvmord og de som gjør selvmordsfors $\varnothing \mathrm{k}$, utgjør to forskjellige populasjoner (Beautrais, 2001). Det er allikevel overlapp mellom gruppene, og noen har estimert at $10-15 \%$ av fors $\varnothing$ kere til slutt vil gjennomf $\varnothing$ re selvmord (Maris et al., 2000). Disse tallene er imidlertid ikke nøyaktige. Hawton et al. (2003) fulgte en stor gruppe selvmordsfors $\varnothing$ kere innlagt på medisinsk akuttpost, og fant at kun $3 \%$ til slutt tok sitt eget liv. Blant dem som gjorde gjentatte selvmordsfors $\varnothing \mathrm{k}$ var selvmordsraten imidlertid $6 \%$. Høyrisikogruppen for gjennomført selvmord har følgende profil: eldre og mann, bruk av mer d $\varnothing$ delige metoder og $\mathrm{d} \varnothing \mathrm{d}$ ved første fors $\varnothing \mathrm{k}$. Selvmordsfors $\varnothing$ kere tenderer mot å være yngre og kvinne, bruker mindre dødelige metoder og overlever (Beautrais, 2001).

En annen forskjell mellom selvmordsfors $\varnothing$ kere og dem som gjennomf $\varnothing$ rer selvmord, er i hvilken grad de søker behandling. En psykologisk autopsistudie av selvmord blant unge voksne viste at mindre enn en tredel var under behandling på det tidspunktet selvmordet skjedde.

Mindre enn halvparten hadde vært i kontakt med en behandler i løpet av det siste året, og en tredel hadde aldri vært vurdert av noen behandler (Lesage et al., 1994; Ménard-Buteau \& Loyer, 1994).
Kronisk suicidale pasienter med UPF søker derimot i stor grad behandling (Zanarini et al., 2001). Selv om de fleste av dem som gjør gjentatte selvmordsfors $\varnothing \mathrm{k}$ slutter med suicidalatferd etter en tid, blir det for noen en livsstil som kan vedvare i årevis (Maris, 1981).

\section{Forskning om kronisk suicidalitet ved UPF}

Kronisk suicidalitet er ett av diagnosekriteriene ved UPF. Den presise angivelsen i DSM-IV-TR (American Psychiatric Association, 2000, kriterium 5) er "gjentatt suicidal atferd, -demonstrasjoner eller -trusler, eller selvskadende atferd"). Kroniske selvmordstanker og trusler om selvmord er vanlige, og $85 \%$ har selvmordsfors $\varnothing \mathrm{k}$ i sykehistorien (Soloff et al., 2000).

Årsaksforholdene rundt kronisk suicidalitet er ikke klarlagt, heller ikke ut fra dagens kunnskap om årsakene til UPF. Imidlertid er det en høyere forekomst av selvmordsfors $\varnothing \mathrm{k}$ blant UPF-pasienter som har opplevd seksuelle overgrep i barndommen (Soloff et al., 2002). Det er uklart om denne sammenhengen reflekterer alvorsgraden av lidelsen som helhet eller om den reflekterer en spesiell virkning av traumet, for kun en liten del av disse pasientene har opplevd alvorlige overgrep (Paris, 2008a).

Hvor suicidale UPF-pasienter er, varierer over tid. Funn fra to sentrale studier viser at UPF-pasienter tenderer til å bli bedre over tid, og at symptomenes styrke vokser og avtar avhengig av livshendelser (Skodol et al., 2005; Zanarini et al., 2005).

Selv om UPF-pasienter tenderer til å ha selvmordstanker og -handlinger når de er deprimerte, kan ikke denne "komorbiditeten" forklare pasientenes kroniske suicidalitet. UPF-pasientenes affektive symptomer er fenomenologisk sett forskjellige fra symptomene ved stemningslidelser. I stedet for en vedvarende depresjon ser man raske stemningsskifter som respons på livshendelser (Gunderson \& Phillips, 1991). Denne forskjellen kan bidra til å forklare hvorfor pasienter med personlighetsforstyrrelser ikke responderer på antidepressive medikamenter på samme måte som pasienter med en
akse-II-diagnose (Shea et al., 1990).

Personer med UPF er kjennetegnet av vedvarende affektiv ustabilitet (Koenigsberg et al., 2002) og en sterk sensitivitet overfor omgivelsene. Dette er hva Linehan (1993) kaller "emosjonell dysregulering", som er en vesentlig underliggende temperamentsfaktor i denne lidelsen (Crowell et al., 2009).

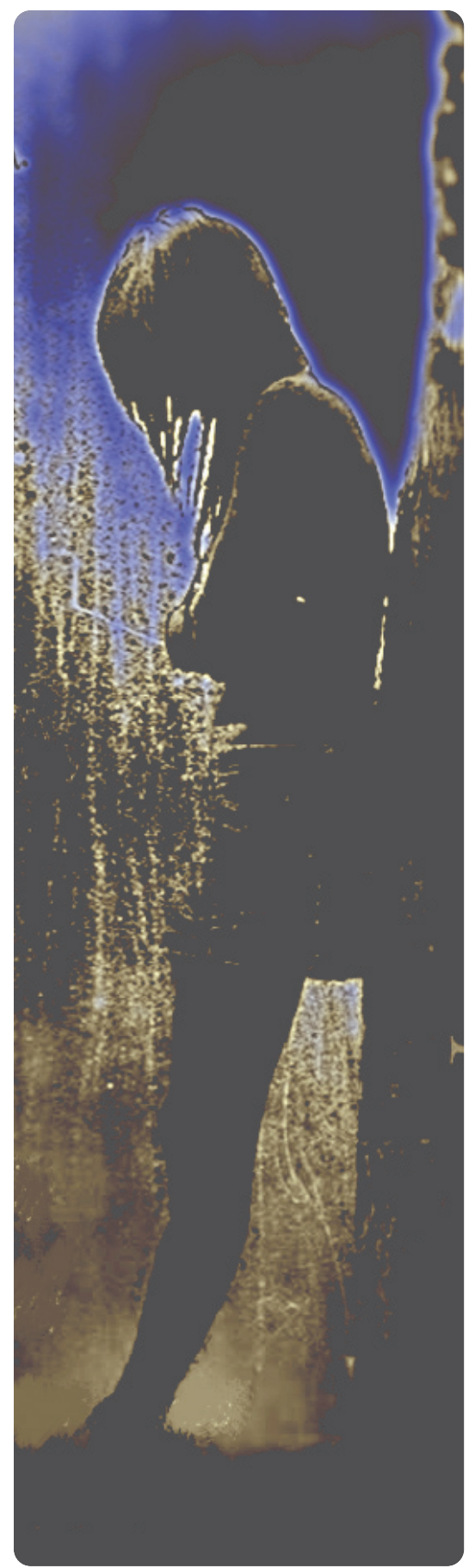




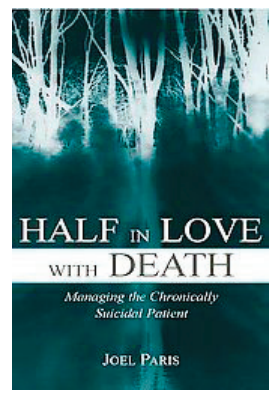

Det kroniske og langvarige spiller inn; det ser ut til å være en sterk sammenheng mellom tidlig debuterende dystymi og cluster-B personlighetsforstyrrelser, mens det ikke er noen slik sammenheng når det gjelder avgrensede episoder med depresjon (Pepper et al., 1995).

I to store oppfølgingsstudier fant man en selvmordsrate på $10 \%$ blant UPFpasienter (Stone, 1990; Paris \& ZweigFrank, 2001). Dette er også bekreftet i andre studier (Paris, 2003). I en retrospektiv studie fant man en rate på $3 \%$ (McGlashan, 1986), mens det i en prospektiv studie ble funnet en rate på $4 \%$ (Zanarini et al., 2005). Like fullt er det slik at UPF-pasienter vanligvis ikke tar livet av seg på det tidspunktet behandlerne er mest redde for at noe slikt kan skje. I stedet skjer de fleste selvmord sent i lidelsens forl $\varnothing \mathrm{p}$. Trusler om - og fors $\varnothing \mathrm{k}$ på selvmord er hyppigst tidlig i forløpet mens pasientene er i tjueårsalderen, mens de fleste selvmord skjer mens pasientene er i trettiårene (Paris, 2003). I det store og hele skjer bare et fåtall selvmord mens pasientene er under aktiv behandling. De fleste selvmord er assosiert med manglende bedring etter en serie mislykkede behandlinger. Det er derfor ikke lett å predikere hva som vil bli utfallet av kronisk suicidalitet ved UPF.

\section{Kronisk suicidale pasienters indre verden}

Hva er meningen med kronisk suicidalitet? I et av de tidligste bidragene til forståelsen av dette beskrev Schwartz et al. (1974) pasienter med "suicidal karakter", det vil si pasienter der suicidalitet er en del av personlighetsstrukturen framfor et symptom på depresjon. Fine og Sansone (1990) beskrev også suicidalitet som et karaktertrekk som ikke så lett lar seg fjerne siden den fyller en funksjon for pasienten. De bemerket at behandlingstilnærminger som er utviklet for å håndtere akutt suicidalitet, ikke passer for kronisk suicidale pasienter med UPF.

Man kan anta at kronisk suicidalitet har tre funksjoner. Den første er å håndtere smertefulle følelser. Vi har beskrevet en liknende funksjon for kutting, men disse mekanismene kan også være i virk- somhet ved overdoser eller selvmordstanker. Pasienter med UPF har ustabile og usedvanlig intense følelser (Linehan, 1993), og selvmordstanker kan gi en beroligende følelse av at det finnes en måte å unnslippe lidelsen på. Man kunne sitere John Keats' "Ode to a nightingale" og si at noen UPF-pasienter er "halvveis forelsket i en fredfull død" ("half in love with easeful death") (Paris, 2006).

Den andre funksjonen som kronisk suicidalitet kan fylle, er kommunikasjon. Som vi har vært inne på, skjer selvmordsfors $\varnothing \mathrm{k}$ blant disse pasientene i en mellommenneskelig kontekst, og kan uttrykke fortvilelse når pasienten ikke forventer å få hjelp på noen annen måte (Gunderson \& Links, 2008). Noen ganger er budskapet rettet til en kjæreste, andre ganger til en behandler. I begge tilfelle kan det være at pasientene tror de må skru volumet på full styrke for å bli hørt.

Den tredje funksjonen til kronisk suicidalitet er å gi en opplevelse av kontroll. Hvis pasientens livskvalitet er lav (med arbeidsløshet og problemer i nære relasjoner), kan pasienten utvikle en følelse av at livet er meningsløst og en følelse av indre tomhet. Når pasienter ikke opplever å ha kontroll over livet, kan det å kunne velge om man skal d $\varnothing$ eller fortsette å leve gi en følelse av å ha innflytelse over hva som vil skje. Symptomene på kronisk suicidalitet avtar når livet blir bedre for pasienten (Paris, 2003). Når pasientene i $\varnothing$ kende grad opplever å mestre sine liv, har de ikke lenger behov for å være herre over d $\varnothing$ den.

\section{En case}

Bridget arbeidet med psykisk utviklingshemmede, men hun hadde store problemer i sitt privatliv. Hun vekslet mellom impulsivt inngåtte intime relasjoner og perioder med isolasjon. Bridget hadde ikke kontakt med sin egen familie og hadde få venner. Hennes mønster var å raskt gå inn i forhold til menn, for så like raskt å bli skuffet over dem. Bridget hadde hatt tanker om å ta sitt eget liv siden tidlig i tenårene, og disse tankene kom daglig. I lang tid hadde hun regelmessig kuttet seg i håndleddene, og en rekke ganger hadde hun tatt en overdose i nærvær av kjærester. Hver av disse episodene startet med intense og smertefulle følelser hun ikke orket å bære. Bridget fantaserte ofte om at døden skulle gjøre slutt på hennes følelse av tomhet. Hun følte trøst ved tanken på at hun ikke var fanget i et håpløst liv.

\section{Behandlingsimplikasjoner}

Kronisk suicidalitet er en alvorlig klinisk utfordring. Maltsberger og Buie (1974) har beskrevet hvilken belastning dette kan være for klinikere. Behandlere kan bli utslitte av pasientenes kroniske trusler om selvmord. Dette skaper til tider en følelsesmessig tilbaketrekning hos behandleren, som så $\varnothing$ ker pasientens følelse av å være forlatt.

Behandlere som behandler kronisk suicidale pasienter, forventes å kunne vurdere selvmordsrisiko. Men vi mangler solid evidens for at dette er mulig og for at de tiltakene som er laget for å hindre selvmord har noen effekt. Dette er ikke så overraskende i og med at kroniske selvmordstanker ikke er et forbigående fenomen ved en depressiv episode, men er rotfestet i personlighetsstrukturen. Det har derfor ingen hensikt å fokusere all innsatsen på spørsmålet om dødelighet. I tillegg kan intervensjoner tilpasset en akutt situasjon, være dårlig tilpasset eller virke mot sin hensikt i en kronisk situasjon.

Et av de vanskeligste spørsmålene er hvilken verdi sykehusinnleggelse har for disse pasientene. Selvmordsfors $\varnothing \mathrm{k}$ er en av hovedårsakene til at UPF-pasienter innlegges i sykehus (Hull et al., 1996). Noen behandlingsveiledere for UPF anbefaler helt spesifikt sykehusinnleggelse for behandling av selvmordstrusler og -fors $\varnothing \mathrm{k}$. Men disse anbefalingene er ikke basert på kontrollerte studier som har vist at innleggelse er hensiktsmessig.

Tanken om at behandlingen av kronisk suicidale pasienter "må sette sikkerheten i høysetet", reiser spørsmålet om det å legge inn pasienten i sykehus faktisk $\varnothing$ ker sikkerheten for vedkommende. Som vi alt har vist, tyder ikke oppfølgingsstudier på at pasienter vanligvis gjennomfører selvmord på det tidspunktet hvor trusler, suicidale gester og fors $\varnothing \mathrm{k}$ er mest framtredende (Paris, 2003). 
Det finnes heller ikke evidens for at sykehusinnleggelse forebygger selvmord. Innleggelse kan faktisk ha en negativ effekt i gruppen av kronisk suicidale pasienter. Dawson og MacMillan (1993) observerte at sykehusomgivelsene har en tendens til å skape en "malign regresjon" der pasienten $\varnothing$ ker sin selvskadende atferd som respons på et behandlingsmiljø som $\varnothing$ ker omsorgen når selvskadingen $\varnothing$ ker. Linehan (1993) har påpekt at innleggelse synes å forsterke den atferden behandlerne prøver å redusere.

En borderlinepasient som hadde fullført et vellykket behandlingsforl $\varnothing p$, publiserte en artikkel basert på egne erfaringer som forbruker av helsetjenester. Der beskrev hun hvordan gjentatte sykehusinnleggelser gjorde henne verre: "Ikke legg inn en pasient med UPF mer enn 48 timer. Mine selvdestruktive episoder - den ene fulgte rett etter den andre startet først etter mine første innleggelser der jeg lærte at systemet var forpliktet til å respondere på selvskadingen" (Williams, 1998).

Det er et problem for klinikere at selv om sykehusinnleggelse ikke ansees som effektiv behandling, kan det å nekte innleggelse føre til en maktkamp. Gunderson og Links (2008) foreslo følgende paradoksale intervensjon: Behandleren tilbyr å legge inn pasienten på grunn av hennes suicidalitet, men lar henne samtidig få vite at innleggelse ikke er til hjelp (i håp om at pasienten da vil takke nei til tilbudet). Maltsberger (1994a, 1994b) er imidlertid helt i mot gjentatte innleggelser ut fra at man ikke kan behandle kronisk suicidale pasienter uten å akseptere en viss kalkulert risiko for selvmord. Kernberg (1987) har også gått ut mot sykehusinnleggelse og anbefaler at behandlere forklarer familier at de ikke kan ta ansvar for at pasienten overlever.

Sykehusinnleggelse vil bare kunne være nyttig hvis den kan gi pasienten anledning til å motta effektiv medikamentell behandling, slik det er tilfellet med andre alvorlige psykiske lidelser. På den annen side har ikke medikamenter mot UPF vist liknende spesifikke effekter som man har sett med medikamenter mot schizofreni eller alvorlig depresjon
(Paris, 2008b). Farmakologiske midler har en viss virkning, men først og fremst ved å redusere impulsivitet, og man har ikke observert remisjon som følge av medikamentell behandling. Det er heller ikke helt nødvendig med sykehusinnleggelse for å få gitt pasientene disse medikamentene.

Vanligvis bør klinikere tilby UPF-pasienter poliklinisk behandling og tolerere en viss forhøyet risiko for selvmord. De bør så fors $\varnothing$ ke å behandle de underliggende årsakene til pasientens kroniske suicidalitet. Tyrer et al. (2000) har ut fra faren for nytteløse reinnleggelser anbefalt at UPF-pasienter i stedet følges tett opp i ambulant behandling. Det er også en anselig mengde evidens for nytten av en rekke polikliniske psykoterapeutiske behandlingsmåter for å redusere både selvskade og selvmordsfors $\varnothing$; særlig gjelder dette dialektisk atferdsterapi (DBT) og mentaliserings-basert terapi (MBT) spesielt utviklet for UPF (Paris, 2008b). Der man ved poliklinisk behandling ikke har klart å håndtere suicidalkriser, har dagbehandling vist seg å være til hjelp, og man har observert en reduksjon $\mathrm{i}$ antall selvmordsfors $\varnothing \mathrm{k}$ (Piper et al., 1996; Bateman \& Fonagy, 1999).

Fordi behandlerens respons på pasientens suicidalitet kan bidra til å forsterke den, advarer de fleste eksperter på UPF pasientene mot å opps $\varnothing$ ke medisinske akuttmottak og sykehus. Rachelin (1984) påpekte at fors $\varnothing \mathrm{k}$ på å forebygge selvmord for enhver pris kan forringe pasientens livskvalitet. Dessuten er det vanskelig å gi effektiv behandling i en situasjon med vedvarende konflikter og uro. Hendin (1981) beskrev situasjoner der behandleren gjør alt for å hindre selvmord som en «tvangstrøye» fordi pasienten dermed blir den som styrer terapeutens atferd.

De juridiske sidene ved kronisk suicidalitet vekker ofte mye bekymring. Gutheil (1992) påpekte at domstolene må ta inn over seg hvilke særskilte dilemmaer klinikere står overfor når de behandler en kronisk suicidal pasient. Han anbefalte en rekke tiltak for å unngå søksmål: nøyaktig journalføring, hyppig rådføring med kollegaer og regelmessige møter med pasientens familie.
Disse konklusjonene er i samsvar med antagelsene om suicidalitetens funksjoner som vi presenterte ovenfor. Hvis det er slik at selvmordstanker fungerer som en fluktrute fra psykisk smerte, $b \varnothing r$ behandlingen sentreres om problemløsningsstrategier for å kontrollere intense og ustabile affekter. Hvis suicidaliteten i større grad handler om en følelse av ikke å bli sett og forstått, kan behandlingen fokusere på empatisk forståelse. I den grad suicidaliteten representerer en måte å skape en følelse av kontroll på, kan behandleren vise respekt for dette behovet og ha fokus på å lære pasienten bedre måter å få kontroll over livet på.

Linehan (1993) foreslår å nærme seg suicidalitet behandlingsmessig gjennom såkalt atferdsanalyse - det vil si ved å få en klarere forståelse for hva som utløser en selvmordstrussel og utvikle mer effektive strategier for å mestre problemene som utløste dette. Behandleren validerer følelsene som utløste suicidaliteten, identifiserer forholdene som førte fram til de negative følelsene, og arbeider for å finne nye løsninger på problemene. Når det som har forårsaket suicidaliteten er identifisert, går behandlingen inn i en problemløsningsfase.

I siste instans innebærer behandlingen av kronisk suicidalitet hos UPF-pasienter et paradoks. Behandlere prøver å behandle selve suicidaliteten, men for at de skal kunne hjelpe pasienten til å leve videre må de respektere at pasienten i stedet kan velge døden. Siden mange UPF-pasienter til slutt blir bra, kan kronisk suicidalitet gjøre oss bekymret, men det bør ikke gjøre oss pessimistiske.

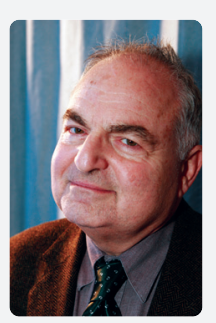
Joel Paris er professor psykiatri og leder for Department of Psychiatry, McGill University, Montreal, Canada. Han er en internasjonalt anerkjent ekspert på forløpsstudier av pasienter med ustabil personlighetsforstyrrelse og på behandling av denne pasientgruppa. Han har skrevet en rekke sentrale artikler og bøker på feltet, bl.a. Half in love with death (2006). 


\section{Referanser}

American Psychiatric Association. (2000). Diagnosti and Statistical Manual of Mental Disorders. 4th ed., text revision. Washington, DC: American Psychiatric Press.

American Psychiatric Association. (2001). Practice guideline for the treatment of patients with borderline personality disorder. Am J Psychiatry, 158 (suppl), 1-52 Bateman, A., \& Fonagy, P. (1999). Effectiveness of partial hospitalization in the treatment of borderline personality disorder: a randomized controlled trial. Am J Psychiatry, 156, 1563-9.

Beautrais, A.L. (2001). Suicides and serious suicide attempts: two populations or one? Psychol Med, 31, $837-45$

Beck, A.T., Resnik, L. \& Lettieri, D.J. (1974). The prediction of suicide. Bowie, MD: Charles Press Publishers. Brodsky, B.S., Malone, K.M., Ellis, S.P., Dulit, R.A., \& Mann, J.J. (1997). Characteristics of borderline personality disorder associated with suicidal behavior. Am J Psychiatry, 154, 1715-9.

Brown, M.Z., Comtois, K.A., \& Linehan, M.M. (2002). Reasons for suicide attempts and nonsuicidal selfinjury in women with borderline personality disorder. J Abnorm Psychol; 111, 198-202.

Crowell, S.E., Beauchaine, T.P., \& Linehan, M.M. (2009). A biosocial developmental model of borderline personality: Elaborating and extending Linehan's theory. Psychological Bulletin, 135, 495-510.

Dawson, D., \& MacMillan, H.L. (1993). Relationship management of the borderline patient: from understanding to treatment. New York, Brunner/Mazel.

Favazza, A.R. (1996). Bodies under siege: self-mutilation and body modification in culture and psychiatry. 2nd ed. Baltimore: Johns Hopkins University Press.

Fine, M.A., \& Sansone, R.A. (1990). Dilemmas in the management of suicidal behavior in individuals with borderline personality disorder. Am J Psychotherapy, $44,160-71$.

Goldstein, R.B., Black, D.W., Nasrallah, A., \& Winokur, G. (1991). The prediction of suicide. Arch Gen Psychiatry, 48, 418-22.

Gunderson, J.G., \& Phillips, K.A. (1991). A current view of the interface between borderline personality disorder and depression. Am J Psychiatry, 48, 967-75. Gunderson, J.G., \& Links, P. (2008). Borderline personality disorder: a clinical guide, 2 nd edition. Washington, DC: American Psychiatric Press.

Gutheil, T.G. (1992). Suicide and suit: liability after self-destruction. In Jacobs D. (ed.). Suicide and clinica practice. Washington, DC: American Psychiatric Press, $147-67$.

Hawton, K., Zahl, D., \& Weatherall, R.(2003). Suicide following deliberate self-harm: long-term follow-up of patients who presented to a general hospital. Brit J Psychiatry, 182, 537-42.

Hendin, H. (1981). Psychotherapy and suicide. Am J Psychother, 35, 469-80.

Hintikka, J., Pesonen, T., Saarinen, P., Tanskanen, A. Lehtonen, J., \& Viinamaki, H. (2001). Suicidal ideation in the Finnish general population. A 12-month followup study. Soc Psychiatry Psychiatr Epidemiol, 36, 590-4 Hull, J.W., Yeomans, F., Clarkin, J., Li, C., \& Goodman, G. (1996). Factors associated with multiple hospitalizations of patients with borderline personality disorder Psychiatr Serv; 47, 638-41.
Isometsä, E.T., \& Lonnqvist, J.K. (1998). Suicide attempts preceding completed suicide. Brit J Psychiatry, 173, 531-5. Kernberg, O.F. (1987). Diagnosis and clinical management of suicidal potential in borderline patients. In Grotstein JS, Solomon MF (eds.). The borderline patient: emerging concepts in diagnosis, psychodynamics and treatment. New York: Psychoanalytic Inquiry Book Series, 69-80.

Kessler, R.C., Berglund, P., Borges, G., Nock, M., \& Wang, P.S. (2005). Trends in suicide ideation, plans, gestures, and attempts in the United States, 1990. 1992 to 2001-2003. JAMA, 293, 2487-2495.

Koenigsberg, H.W., Harvey, P.D., Mitropoulou, V., Schmeidler, J., New, A.S., \& Goodman, M. (2002). Characterizing affective instability in borderline personality disorder. Am J Psychiatry, 159, 784-788.

Leibenluft, E., Gardner, D.L., \& Cowdry, R.W. (1987). The inner experience of the borderline self-mutilator. J Personal Disord, 1, 317-24.

Lesage, A.D., Boyer, R., Grunberg, F., Morisette, R. Vanier, C., \& Morrisette, R. (1994). Suicide and mental disorders: a case control study of young men. Am J Psychiatry, 151, 1063-8.

Linehan, M.M. (1993). Cognitive Behavioral Therapy of Borderline Personality Disorder. New York: Guilford.

Maltsberger, J.T., \& Buie, D.H. (1974). Countertransference hate in the treatment of suicidal patients. Arch Gen Psychiatry; 30, 625-33.

Maltsberger, J.T. (1994a). Calculated risk in the treat ment of intractably suicidal patients. Psychiatry, 57 199-212.

Maltsberger, J.T. (1994b). Calculated risk taking in the treatment of suicidal patients: ethical and legal problems. Death Stud, 18, 439-52.

Maris, R. (1981). Pathways to Suicide. Baltimore: Johns Hopkins University Press.

Maris, R.W., Berman, A.L., \& Silverman, M.M. (2000). Comprehensive Textbook of Suicidology. New York: Guilford.

McGlashan, T.H. (1986). The Chestnut Lodge followup study III: long- term outcome of borderline personalities. Arch Gen Psychiatry, 43, 2-30.

Paris, J., \& Zweig-Frank, H. (2001). A twenty-seven year follow-up of borderline patients. Compr Psychiatry, 42, 482-7.

Paris, J. (2003). Personality Disorders Over Time. Washington, DC: American Psychiatric Press.

Paris, J. (2006). Half in Love with Death: Managing the Chronically Suicidal Patient. Mahwah, NJ: Laurence Erlbaum.

Paris, J, (2008a). Treatment of Borderline Personality Disorder: A Guide to Evidence-Based Practice. New York: Guilford Press.

Paris, J. (2008b). Clinical trials in personality disorders, Psychiatric Clinics of North America; 31, 517-26.

Pepper, C.M., Klein, D.N., Anderson, R.L., Riso, L.P., Ouimette, P.C., \& Lizardi, H. (1995). DSM-III-R Axis II comorbidity in dysthymia and major depression. Am J Psychiatry, 152, 239-47.

Piper, W.E., Rosie, J.S., \& Joyce, A.S. (1996). Timelimited day treatment for personality disorders: integra tion of research and practice in a group program. Washington, DC: American Psychological Association. Pokorny, A.D. (1982). Prediction of suicide in psychiatric patients: report of a prospective study. Arch Gen Psychiatry, 40, 249-57.
Rachlin, S. (1984). Double jeopardy: suicide and malpractice. Gen Hosp Psychiatry, 6, 302-7.

Shneidman, E.S. (1973). Deaths of Man. New York: Quadrangle/New York Times.

Schwartz, D.A., Flinn, D.E., \& Slawson, P.F. (1974). Treatment of the suicidal character. Am J Psychotherapy, 28, 194-207.

Shea, M.T., Pilkonis, P.A., Beckham, E., Collins, J.F. Elikin, E., \& Sotsky, S.M. (1990). Personality disorders and treatment outcome in the NIMH Treatment of Depression Collaborative Research Program. Am J Psychiatry, 147, 711-8.

Simeon, D., Stanley, B., Frances, A., Mann, J.J., Winchel, R., \& Stanley, M. (1992). Self-mutilation in personality disorders: psychological and biological correlates. Am J Psychiatry, 149, 221-6.

Skodol, A.E., Gunderson, J.G., Shea, M.T., McGlashan, T.H., Morey, L.C., \& Sanislow, C.A. (2005). The Collaborative Longitudinal Personality Disorders Study (CLPS): overview and implications. Journal of Personality Disorders, 19, 487-504.

Soloff, P.H., Lynch, K.G., Kelly, T.M., Malone, K.M. \& Mann, J.J. (2000). Characteristics of suicide attempts of patients with major depressive episode and borderline personality disorder: a comparative study. Am J Psychiatry, 157, 601-8.

Soloff, P.H., Lynch, K.G., \& Kelly, T.M. (2002). Childhood abuse as a risk factor for suicidal behavior in borderline personality disorder. J Person Disord, 16, 201-14.

Stone, M.H. (1990). The Fate of Borderline Patients. New York: Guilford.

Tyrer, P., Coid, J., Simmonds, S., Joseph, P., \& Marriott, S. (2000). Community mental health teams (CMHTs) for people with severe mental illnesses and disordered personality. Cochrane Database System Rev, 2, CD000270.

Weissman, M.M., Bland, R.C., Canino, G.J., \& Faravelli, C. (1996). Cross-national epidemiology of major depressive and bipolar disorder. JAMA, 276, 298-9.

Welch, S.S. (2001). A review of the literature on the epidemiology of parasuicide in the general population. Psychiatr Serv, 52, 368-75.

Williams, L. (1998). A “classic” case of borderline personality disorder. Psychiatr Serv, 49, 173-4.

Zanarini, M.C., Frankenburg, F.R., Dubo, E.D., Sickel, A.E., Trikha, A., \& Levin, A. (1998). Axis I comorbidity of borderline personality disorder. Am J Psychiatry, 155, 1733-9.

Zanarini, M.C., Frankenburg, F.R., Khera, G.S., \& Bleichmar, J. (2001). Treatment histories of borderline inpatients. Compr Psychiatry, 42, 144-50.

Zanarini, M.C., Frankenburg, F.R., Hennen, J., Reich, D.B., \& Silk, K.R. (2005). The McLean Study of Adult Development (MSAD): overview and implications of the first six years of prospective follow-up. Journal of Personality Disorders, 19, 505-523.

(Artikkelen er oversatt av Henning Herrestad.) 